\title{
A Solitary Fibrous Tumour of the Eyelid
}

\author{
Irene Pecorella ${ }^{a}$ Filippo Cruciani $^{\mathrm{b}}$ Valeria Russo ${ }^{\mathrm{b}}$ \\ ${ }^{a}$ Department of Radiologic, Oncologic and Anatomic Pathology, and ${ }^{b}$ Department of Sense Organs, \\ University of Rome 'Sapienza', Rome, Italy
}

\author{
Key Words \\ Solitary fibrous tumour · Eyelid $\cdot$ CD34 · Progesterone \\ receptor $\cdot \mathrm{Bcl}-2$
}

\begin{abstract}
Objective: To report a case of palpebral solitary fibrous tumour (SFT). Clinical Presentation and Intervention: An elderly man presented with a slow-growing painless mass in the lower conjunctival fornix in the left eye. The lesion was excised and it measured $0.9 \mathrm{~cm}$ in maximum diameter. The microscopic features were characteristic of a benign SFT, with immunohistochemical reactivity for vimentin, CD34 and $\mathrm{BCl}-2$ protein. Nuclear staining for progesterone receptor was also observed. Conclusion: This tumour displayed a benign course, with no recurrence after excision. CD34 immunohistochemistry proved to be a useful adjunct to the microscopic diagnosis.

(c) 2013 S. Karger AG, Basel
\end{abstract}

\section{Introduction}

Solitary fibrous tumour (SFT), a benign mesenchymal fibroblast-like tumour, was first described as a primary mesothelial spindle-cell tumour of the pleura in 1931 [1]. With the advent of immunohistochemistry a fibroblastic origin, occasionally with myofibroblastic differentiation, was firmly established. It was also established that SFTs are ubiquitous neoplasms with both pleural and extrapleural distribution, the most common extrapleural sites being the orbits and the extremities. Other sites that have been reported include pericardium, lung, mediastinum, peritoneum and retroperitoneum, upper respiratory tract (nasal cavity, sinuses and nasopharynx), meninges, thyroid, parotid, adrenal gland, breast, genito-urinary tract (kidney, vulva, urinary bladder and the prostate) and liver. Herein we report a case of SFT of the eyelid, a site of origin that has rarely been described.

\section{Case Report}

A 78-year-old man presented with a slow-growing painless hard-elastic, palpable mass in the lower conjunctival fornix in the left eye, which was first noticed 1 year earlier. The visual field was intact and ocular movements were preserved. Surgical excision of the tumour revealed a well-defined, non-encapsulated, ovoid mass, white-grey in colour upon sectioning, measuring $0.9 \mathrm{~cm}$ in diameter, located in the subcutaneous tissue of the lower eyelid. There was no evidence of orbital or local tissue invasion seen. Postoperatively the patient did well and showed no signs of tumour recurrence at 24-month follow-up, with good cosmetic and functional results.

Microscopically, the SFT was a moderately cellular tumour, composed of patternless uniform, bland-looking bipolar spindle or oval cells with indistinct eosinophilic cytoplasm, in a heavily collagenized stroma. Abundant blood vessels and rare irregular branching vessels in a haemangiopericytoma (HPC)-like (staghorn) pattern were observed (fig. 1). The dilated vessels were more prominent at the periphery of the mass. No multinucleated giant

\begin{tabular}{ll}
\hline KARGER & $\begin{array}{l}\text { (c) 2013 S. Karger AG, Basel } \\
\text { 1011-7571/13/0232-0170\$38.00/0 Operger }\end{array}$ \\
E-Mail karger@karger.com & $\begin{array}{l}\text { This is an Open Access article licensed under the terms of the } \\
\text { www.karger.com/mpp }\end{array}$ \\
$\begin{array}{l}\text { Creative Commons Attribution-NonCommercial 3.0 Un- } \\
\text { ported license (CC BY-NC) (www.karger.com/OA-license), } \\
\text { applicable to the online version of the article only. Distribu- } \\
\text { tion permitted for non-commercial purposes only. }\end{array}$
\end{tabular}

Prof. Irene Pecorella

Department of Radiologic, Oncologic and Anatomic Pathology

University of Rome 'Sapienza'

Viale Regina Elena 324, IT-00161 Rome (Italy)

E-Mail irene.pecorella@ uniroma1.it 


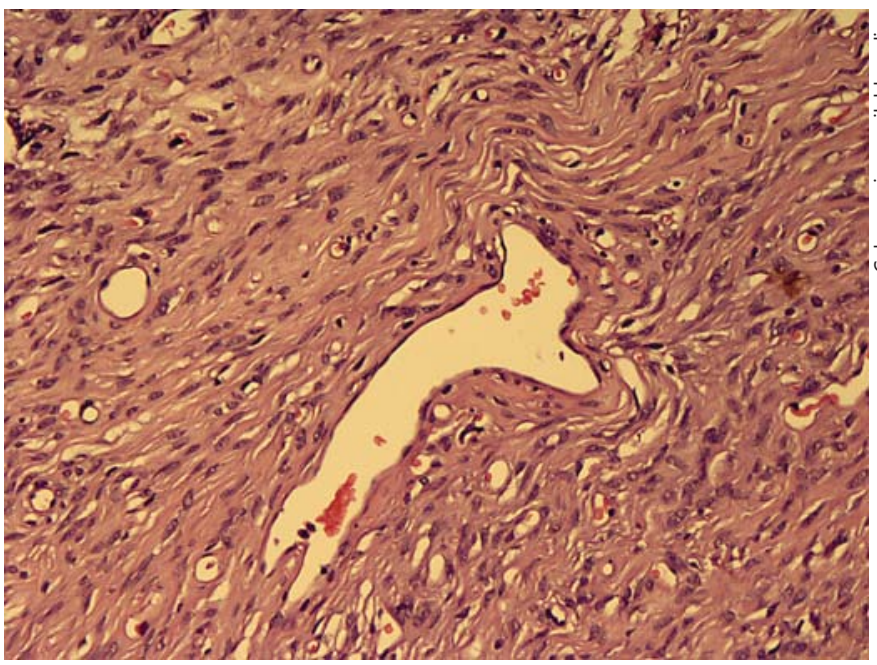

Fig. 1. Spindle- to ovoid-shaped cells interspersed with irregular vascular channels and ectatic or compressed, thin-walled vessels.

cells, mitotic activity, pleomorphism, or atypia were identified. There was strong and uniform immunohistochemical reactivity for vimentin, CD34 and B-cell lymphoma 2 (Bcl-2) protein on paraffin-embedded tissue sections (fig. 2a, b). Nuclear staining for progesterone receptor (PR) was also observed (fig. 2c). Staining for S-100 protein, CD99, KIT/CD117 and actin smooth muscle was negative. The number of proliferating Ki-67-positive nuclei was low, with values averaging $1 \%$.

\section{Discussion}

The tumoural mass in the eyelid of this patient was microscopically consistent with an SFT. However, in consideration of the unusual location, CD34 immunotyping of the neoplastic cells was performed to confirm the diagnosis. Indeed, a widely distributed family of CD34+ interstitial spindle cells (so-called 'dendritic interstitial cells') are likely to be the cell of origin of SFT.

CD34, a myeloid progenitor cell antigen that is present in normal and neoplastic endothelial cells and in some other mesenchymal cells, including subsets of fibroblasts, is consistently positive in SFT. In addition to CD34, this case was also immunoreactive for vimentin and $\mathrm{Bcl}-2$, as noted previously in similar tumours [2].

Before the widespread use of immunohistochemical studies and CD34 labelling, the diagnosis of orbital and periorbital SFT based solely on the histopathological findings was confused with other benign lesions, such as fibrous histiocytoma and HPC. SFT as an entity is rarely diagnosed clinically.

Solitary Fibrous Tumour of the Eyelid
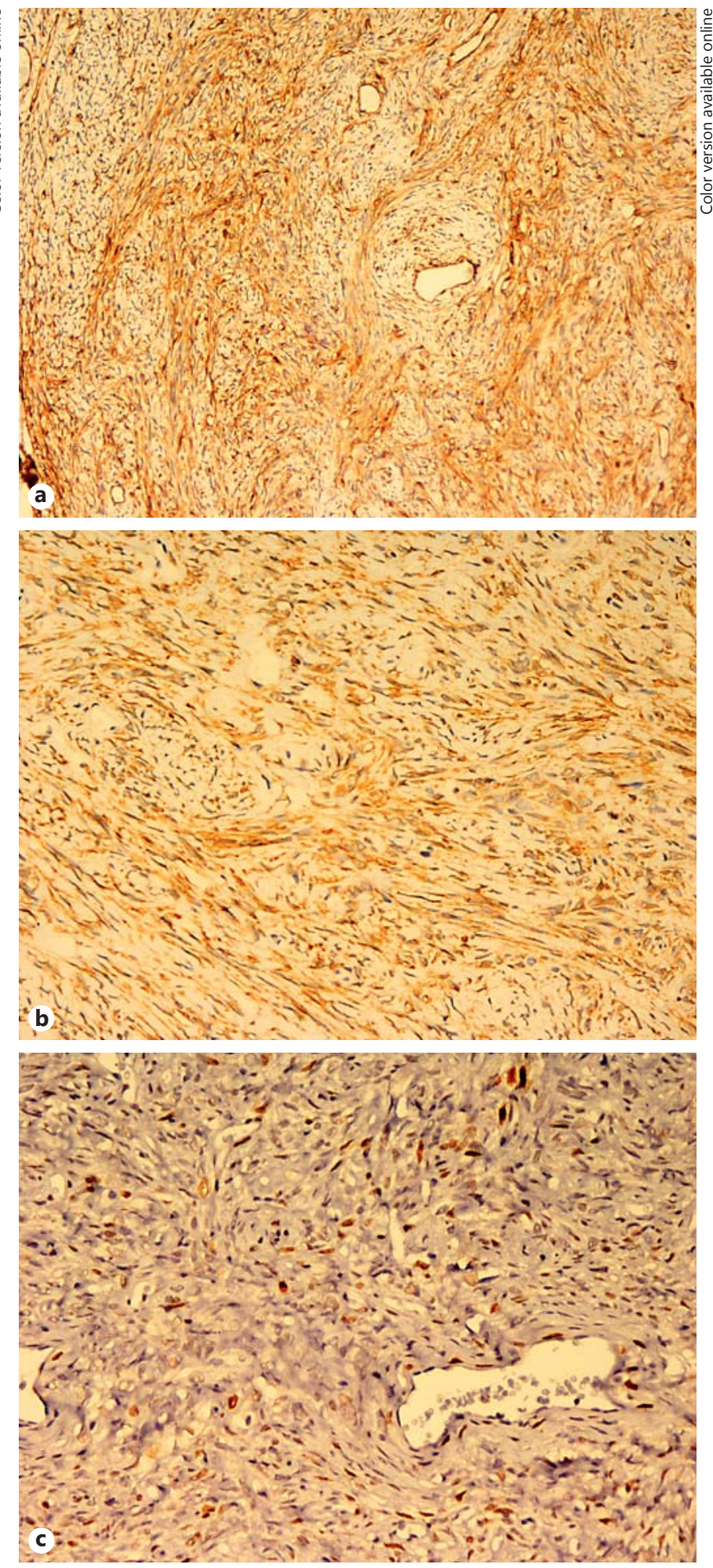

Fig. 2. Strong positive immunolabelling (brown staining) of tumour cells is evident with both CD34 (a) and Bcl-2 (b). Bcl-2 protein is associated with prolonged cell survival due to inhibition of apoptosis. c Numerous tumour cell nuclei are immunostained for PR. Avidin-biotin-peroxidase-DAB. $\mathbf{a} \times 100$. b $\times 250$. $\mathbf{c} \times 400$.

Med Princ Pract 2014;23:170-173 
Table 1. Eyelid lesions of the HPC-SFT spectrum described in the literature

\begin{tabular}{|c|c|c|c|c|c|c|c|}
\hline Ref. & Site & $\begin{array}{l}\text { Size, } \\
\mathrm{cm}\end{array}$ & $\begin{array}{l}\text { Patient's } \\
\text { age }\end{array}$ & $\begin{array}{l}\text { Patient's } \\
\text { sex }\end{array}$ & Complaints & Outcome & $\begin{array}{l}\text { Histology/ } \\
\text { immunohistochemistry }\end{array}$ \\
\hline 6 & $\mathrm{Rl}$ & 3 & 35 & M & enlarging painless mass for 12 months & FP for 6 months & $\begin{array}{l}\text { HPC-SFT (indeterminate)/ } \\
\text { CD34+ }\end{array}$ \\
\hline 7 & $\mathrm{Lu}$ & 2 & 78 & $\mathrm{~F}$ & painless mass for 8 years & not removed & GCA/CD34+- \\
\hline 8 & $\mathrm{Rl}$ & 2 & 40 & M & periocular painless mass for 6 months & $\begin{array}{l}\text { FP for at least } \\
24 \text { months }\end{array}$ & SFT/CD34+ \\
\hline 9 & & & 30 & M & $\begin{array}{l}\text { oedematous, pedunculated, painless } \\
\text { masses already resected twice }\end{array}$ & FP for 8 months & GCA/CD34+, Bcl-2+ \\
\hline 10 & $\mathrm{Ll}$ & 1 & 31 & $\mathrm{~F}$ & enlarging mass for 3 months & FP at 8 months & HPC/CD34- \\
\hline 11 & $\mathrm{Rl}$ & 1.4 & 24 & M & painless conjunctival mass for 12 months & & GCA/CD34+, Bcl-2+ \\
\hline
\end{tabular}

Recently, it has been described that steroid hormone receptors, PR in particular, may be expressed by extrapleural SFT. It has been proposed that progesterone may participate as a growth factor in many CD34+ neoplasms. According to the study of Bongiovanni et al. [2], $\mathrm{PR}+$ is a feature of SFT showing a higher proliferative activity and a trend toward recurrence. We also found the present tumour to be PR+; however, the patient failed to show evidence of disease after 24 months of follow-up. Bcl-2 protein displays a restricted pattern of expression in adult mammalian tissues, being confined to stem cells, to long-lived cells, and to hormone-responsive tissues. The expression of $\mathrm{Bcl}-2$ in this case could be related to the presence of $\mathrm{PR}$ in the neoplastic tissue.

SFT occurs most commonly in adults and shows a slight male predominance as in this case. It is microscopically composed of uniform spindle cells arranged in interlacing fascicles. It exhibits alternating hypercellular areas and hypocellular areas with abundant thick, often keloid-like, hyalinized collagen. Furusato et al. [3] recently reviewed 41 fibroblastic orbital tumours, retrieved from the consultation file of the Armed Forces Institute of Pathology, originally diagnosed as HPC, fibrous histiocytomas and giant cell angiofibromas. However, all the lesions showed overlapping morphological and immunohistochemical features, including CD34 positivity, varying in cellularity, stromal collagen, and the presence of giant cells. Similarities with giant cell fibroblastoma were also evident. The majority of tumours within the HPC-SFT spectrum are defined as 'indeterminate', as their histologic or antigenic profiles are not classic for HPC or SFT. Despite considerable morphologic overlap of SFT with HPC, the differential diagnosis can be made using CD34 staining, which is more often patchy and weak in HPC. Furthermore, HPC shows more diffuse vascularity with more prominent staghorn vessels and rounded tumour cells. Of note, according to the World Health Organization, most of the tumours formerly diagnosed as HPC are considered to be extrapleural cellular variants of SFTs. Lipomatous HPC is another entity presently considered to represent, in most cases, a fat-containing variant of SFT.

CD34 is an efficient tool for differential diagnosis, being present in $79-100 \%$ of SFT cases [4]. Unfortunately, it is not entirely specific for SFT or lesions in the HPCSFT spectrum and expresses in a variety of spindle cell neoplasms, such as HPC, dermatofibrosarcoma protuberans, Kaposi's sarcoma, spindle cell lipoma, gastro-intestinal stromal tumours, or nerve sheath tumours. Furthermore, malignant transformation of SFT may be associated with conversion of a CD34+ lesion to a CD34- lesion [5].

Eyelid SFT appears to be very infrequent. So far only 6 other cases in the HPC-SFT spectrum have been described in the literature (table 1). Of them, just 1 case was diagnosed as SFT. Previous reports of eyelid lesions from SFT appear to be eyelid extensions or coexisting eyelid 
symptoms affected by a primary orbital lesion [6]. Because of the paucity of reported primary SFT of the eyelid, information concerning etiologic factors, treatment and prognosis is limited and new additions to the literature may prove useful.

\section{Conclusion}

This tumour displayed a benign course, with no recurrence after excision. CD34 immunohistochemistry proved to be a useful adjunct to the microscopic diagnosis.

\section{References}

1 Klemperer P, Rabin CB: Primary neoplasms of the pleura: a report of five cases. Arch Pathol 1931;11:385-412.

-2 Bongiovanni M, Viberti L, Pecchioni C, et al: Steroid hormone receptor in plural solitary fibrous tumours and CD34+ progenitor stromal cells. J Pathol 2002;1982:252.

-3 Furusato E, Valenzuela IA, Fanburg-Smith JC, et al: Orbital solitary fibrous tumor: encompassing terminology for hemangiopericytoma, giant cell angiofibroma, and fibrous histiocytoma of the orbit: reappraisal of 41 cases. Hum Pathol 2011;42:120-128.
4 Heathcote GJ: Pathology update: solitary fibrous tumor of the orbit. Can J Ophthalmol 1997;32:432-435.

5 Girnita L, Sahlin S, Orrego A, et al: Malignant solitary fibrous tumour of the orbit. Acta Ophthalmol 2009;87:464-467.

6 Kakizaki H, Maden A, Ture M, et al: Hemangiopericytoma-solitary fibrous tumor of the eyelid. Ophthal Plast Reconstr Surg 2010;26:46-48.

$>7$ Hayashi N, Borodic G, Karesh JW, et al: Giant cell angiofibroma of the orbit and eyelid. Ophthalmology 1999;106:1223-1229.

$>8$ Kim HJ, Kim HJ, Kim YD, Yim YJ, Kim ST, Jeon P, et al: Solitary fibrous tumor of the orbit: CT and MR imaging findings. AJNR Am J Neuroradiol 2008;29:857-862.
9 Mawn L, Jordan D, Nerad J, et al: Giant cell angiofibroma of the eyelids: an unusual presentation of tuberous sclerosis. Ophthalmic Surg Lasers 1999;30:320-322.

10 Sekundo W, Roggenkamper P, Tschubel K, Fischer HP: Hemangiopericytoma of the inner canthus. Am J Ophthalmol 1996;121:445447.

11 Song A, Syed N, Kirby PA, Carter KD: Giant cell angiofibroma of the ocular adnexae. Arch Ophthalmol 2005;123:1438-1442. 